Олейнік, Марек, і Яручик, Віктор. «Способи ідентифікації селян на польсько-українському пограниччі в XVI-XVIII ст. на прикладі антропонімії Грабовецького старостату». Лінгвостилістичні студії, вип. 13, 2020, с. 112-20.

Olejnik, Marek, and Iaruchyk, Viktor. "Methods of Linguistic Identification of Peasants on the Polish-Ukrainian Borderland in the XVI-XVIII Centuries: the Case Study of the Starostat Grabovetsky Anthroponymy". Linguostylistic Studies, iss. 13, 2020, pp. 112-20.

удК 81'373.23(438)

https://doi.org/10.29038/2413-0923-2020-13-112-120

\title{
СПОСОБИ ІДЕНТИФІКАЦІЇ СЕЛЯН НА ПОЛЬСЬКО-УКРАЇНСЬКОМУ ПОГРАНИЧЧІ В XVI-XVIII СТ. НА ПРИКЛАДІ АНТРОПОНІМІЇ ГРАБОВЕЦЬКОГО СТАРОСТАТУ
}

\author{
Марек Олейнік \\ Університет Марії Кюрі-Склодовської, \\ Люблін, Республіка Польща \\ Віктор Яручик \\ Волинський національний університет імені Лесі Українки, \\ Луцьк, Україна
}

У статті розглянуто проблеми ідентифікації селян у XVI-XVIII століттях на території Грабовського старостату. У дослідженні сконцентровано увагу на розгляді архівних матеріалів, які дійшли до наших днів. Було виокремлено кілька головних чинників, що сприяли утворенню прізвищ селян. На цей процес важливий вплив мало явище білінгвізму, яке побутувало на досліджуваній території. У роботі використано архівні джерела.

Ключові слова: ономастика, прізвища, номінування, білінгвізм, мовна ідентифікація.

\section{METHODS OF LINGUISTIC IDENTIFICATION OF PEASANTS ON THE POLISH-UKRAINIAN BORDERLAND IN THE XVI-XVIII CENTURIES: THE CASE STUDY OF THE STAROSTAT GRABOVETSKY ANTHROPONYMY}

\author{
Marek Olejnik \\ Maria Curie-Skłodowska University in Lublin, Poland \\ Viktor Iaruchyk \\ Lesya Ukrainka Volyn National University, Lutsk, Ukraine
}

The article highlights the issue of identifying peasant names of the XVI-XVIII centuries on the territory of the Starostat Grabovetsky. The authors of the article focus on the analysis of the archival materials that have survived. Several basic norms that contribute to understanding of peasant names origin have been identified. The emphasis is on the phenomenon of bilingualism, which existed in that area and contributed greatly to this process. The study uses the original source records. The purpose of the article is to elucidate the ways/methods of identifying male names among the peasants, which were typical on the territory of Grabowski Starostat from the XVI to XVIII centuries. Anthroponymic material

(C) Олейнік М., Яручик В., Волинський національний університет імені Лесі Українки, 2020.

Це стаття відкритого доступу на умовах CC BY-NC 4.0 
received from archival sources provides excellent opportunities for research. On the basis of source materials it is possible to define types of town personal names, allocate the means used for their creation, and also distinguish the anthroponyms, taking into account a social status of their carriers.

In Starostat Grabovetsky, the monomial system of authentication prevailed among peasants at the earlier stages (to the middle of XVI cent.). Afterwards, with the necessity of extended authentication, patronymic name, which was evened by appellative, was added, very often naming geography of the person's origin. There were also determinants that specified the status of the person by origin.

Key words: onomastics, surnames, nominations, bilingualism, linguistic identification.

Вступ. Дослідження, які стосуються вивчення особливостей номінації людей, належать до актуальних і в сучасному мовознавстві. Власне цим був мотивований вибір теми нашої статті: аналіз прізвищ представників чоловічого населення Грабовецького старостату в XVI-XVIII століттях.

Матеріал і методи дослідження. Матеріал дослідження становлять документи з Державного архіву в Любліні та Головного архіву давніх актів у Варшаві, а саме: акти міста Грабовець, гродські книги Грабовця та земські книги Грабовця. Також використано огляди староств Грабавецького повіту з 1662 року (список використаних джерел подано в кінці роботи). Ці рукописні матеріали переважно не були дотепер об'єктом зацікавлень ономастів. Стаття $є$ доповненням до монографії під назвою «Антропонімія Грабовецького старостату (XVI-XVIII ст.)» (Olejnik).

Проблемам антропонімії присвятили багато уваги у своїх публікаціях наступні дослідники: Г. Аркушин, Е. Вольніч-Павловська, Л. Дацевіч, М. Койдер, I. Митнік, Я. Ріґер, В. Шуловська. Головними методами дослідження стали: описовий - для систематизації фактичного матеріалу, зіставний - для виділення найпоширеніших способів творення онімних найменувань, частково історично-порівняльний - для встановлення передумов формування реєстру прізвищевих назв.

Мета дослідження. Метою статті передбачено представлення способів ідентифікації представників чоловічої статі серед селян Грабовського старостату з XVI до XVIII століття. Антропонімічний матеріал із архівних джерел дає широкі можливості для досліджень. На їх підставі можна визначити види особових назв, виокремити засоби, що використовуються для їхнього творення, а також розрізнити антропоніми із врахуванням суспільного походження його носіїв.

Розшифрування записів рукописних джерел виявилося доволі складним. Вплив на такий стан речей мало багато чинників, наприклад, відсутність спільних правил польської графіки та орфографії середньопольської доби; документи записувалися багатьма писарями, котрі, переважно, писали нечітко, з деякою непослідовністю.

Результати дослідження і дискусія. Грабовець знаходиться у південно-східній частині Люблінського воєводства. Колись він був містом 
Більського воєводства. Грабовець керувався руським та польським (правдоподібно з 1394 року) правом. Мазовецько-більський князь Владислав I у 1462 році прилучив Грабовець до польської Корони (Jaroszyński 17). Цей факт мав вплив на прихід нових осадників із Мазовеччини. Таке приєднання Більського воєводства до польської Корони призвело до того, що на цій території опинилося населення, яке розмовляло староукраїнською та польською мовами. Це сприяло поширенню білінгвізму. У зв'язку із осадництвом мазовецької шляхти розпочалася полонізація, яка, передусім, охопила руську шляхту та міщанство. Такий стан речей підтверджують топоономастичні дослідження Б. Чопек. У них ідеться про існування на цій території двомовної традиції номінування (Czopek 153). Сільське населення переважно залишалося україномовним.

Важливу роль у формуванні двомовності на території Грабовецького старостату відіграла уніатська холмська дієцезія (1596-1875), що була створена на базі колишньої православної. Важливим чинником, що сприяв білінгвізму, стала поява в Холмі 1639 року однієї з перших публічних шкіл для світської молоді. У цій школі, якою керували василіянці, вивчали польську мову для потреб уніатської дієцезії. Звідси можемо зробити висновок, що еліти греко-католицької церкви послуговувалися польською та українською мовами (Czyżewski). На основі збережених архівів Холмської греко-католицької консисторії можна стверджувати, що писарі у XVII i XVIII ст. були двомовними. Двома мовами найімовірніше користувалися вищі верстви холмського греко-католицького духовенства (Kość, «Polszczyzna» 47).

Ширший, аніж тільки «ієрархічний білінгвізм», припадає на XVII і XVIII ст., коли полонізувалися міщани в Більському воєводстві (Kość, «Z historii» 105). Це демонструють вже згадані результати досліджень топонімії Б. Чопек, а також аналіз грабовецьких текстів 1566-1569 років (Kuraszkiewicz 224). Білінгвізм на початковому етапі обмежувався тільки власною лексикою. Процес засвоєння другої мови наступав i в привілейованих прошарках. До ХIX століття білінгвізм не охопив селян (Czyżewski, i Warchoł 12), що й позначилося на мовних засобах ідентифікації їхнього соціального статусу й корпусу антропонімій них назв.

На приналежність до селян вказували станові кваліфікації: chłop, parobek, pracowity, roboczy, zarodnik, cmethos, laboriosus. Ідентифікаційні формули селян складалися з одно- чи багатоскладових структур. Це зобумовлювалося часовим чинником. У XVI та в першій половині XVII ст. фіксовано випадки, коли селян називали тільки іменем, наприклад: Oniszko 1545 KZG2 293; Thomko 1545 KZG2 293; Jurko 1545 KZG2 293; Hacz 1570 KGR73 12; Panasz 1570 KGR73 12; Hlibko 1570 KGR73 12.

Найчастіше перед іменем вжито станову назву, наприклад: Laboriosus Kuriło 1568 KZG4 515; Laboriosus Jacobus 1571 KZG1 180; Laboriosus Stanko 1571 KZG1 234; Laboriosus Olesko 1571 KZG1 278; Laboriosus Anton 1571 KZG1 279; Laboriosus Jasko 1575 KZG21 75; Laboriosus Kur3ma 1575 KZG21 84; 
Laboriosus Bakon 1575 KZG21 84; Laboriosus Harassÿm 1575 KZG21 85; Laboriosus Klimko 1586 KGW162 177; Laboriosos Haczko, Chwedko, Zańko 1619 KZG27 1235; Laboriosus Nicolaus 1599 KZG9 848; Laboriosus Kunach 1620 KZG15 506; Laborioso Michałko 1705 KGR104 1006; Labsum Wasko 1714 KGR108 87; Laboriosum Jasko 1732 KGR117 272.

У судових матеріалах для більш детальної ідентифікації селян, застосовували аналітичне географічне визначення, що вказувало, з якого села походить певна особа: Laboriosus Michael de Tuсзетру 1513 KZ1 536; Laboriosus Waszil de Labunye 1542 KZG2 210; Laboriosus Jaczko de villa Stabrow 1571 KZG1 238; Laboriosus Dimko de villa Stabrow 1571 KZG1 238; Laboriosus Petrus de Komorow 1575 KZG21 87; Laboriosi Bartholomei de villa Nieledew 1620 KZG15 387; Laboriosus Iwasko de Xęostany 1620 KZG15 400; Laboriosi Gregorÿ de villa minori Skomorochi 1627 KZG29 803; Laboriosus Kuzma de villa Worochna 1628 KZG29 902; Pracowitÿ Wasko ze wsi Rogowa 1648 KM4 187; Pracowity sienko 3 Swidnik 1657 KM3 217.

Частотні випадки, коли в ідентифікаційній формулі подавали інформацію про те, чиїм підданим був селянин, наприклад: Laboriosus Hricz Subditus et Cmetho gerosi. Joannis C3ec3s3owskj actor 1541 KZG1 88; Laboriosus Nicolaus subditus Nobilis bernardi chmÿel de Grabowcзyk 1566 KZG4 84; Laboriosus Choma de Stabrow Subditus Generosi Stani. Dunkowski Actor 1571 KZG1 234; Laboriosus Olesko de Xezostanÿ Subdit. Nobil. Valentini Komorowskÿ 1578 KZG21 545; Laboriosus Lech de Br3ozowa Wola subditt. Nobilis Andr. Komorowski 1594 KZG23 1489; Laboriosus Jaczko de Beresteçko subditt. Gnosi Stanus. Łasc3 Nieledewski venator 1596 KZG24 284; Laboriosus Michałko de Kxięzostanÿ Subditt. Generosi Joannis Niezabithowski 1606 KZG25 1196; Laboriosus Lucas de villa Komorow Subditus Joan. Niezabytowskÿ 1617 KZG27 33; Laboriosi Jachÿm et Bartholomeus subditi Nobilis Georgy Komorowski in villa Komorow 1617 KZG27 153; Laboriosi Jaczko Kunach chwedko et S3obko Subditi Nlis Jacobi R3imskÿ 1618 KZG27 369; Laboriosum Petrum Soyka de villa Nieledew subditum Gnosorum Barbara de Ozarow consortis olim Gnosi Nicolai Łascz Nieledowski 1623 KZG15 1018.

На початку XVI століття до нечисленних належали ситуації, коли селян ідентифікували за іменем та прізвищем. Починаючи 3 другої половини XVI століття, номінації такого різновиду ставали більш поширеними, наприклад: Misko Sadlo 1545 KZG2 293; ... Iwasko Sakowic3 1548 KZG2 707; Smok Wasil 1570 KGR73 12; Iwan Bołkun 1621 KZG15 833; ... Jasko, Cieslik 1621 KZG15 833; ... Sidor Dacзcзyn 1621 KZG15 833; ... Macko Gresiczuk 1655 KGW175 1479.

Формула, що складалася з імені та прізвища, найчастіше доповнювалася вказівкою, до якого стану ця особа належить, наприклад: Laboriosus Kuзта Borisowic3 1575 KZG21 218; Laboriosus Vasko Czestopÿany 1575 KZG21 254; Laboriosus Sienko Gieros3 1586 KZG22 1021; Laboriosus Hric3 Dudalowic3 1586 KZG22 1022; Laboriosus Nicolaus Dudko 1597 KZG24 507; Laboriosus Jaçko Biłokur 1610 KZG26 64; Laboriosi Misko Boczyło 1644 KZG30 1112; pracowitÿ 
Gr3egor3 Buraçek 1658 KM3 299; Laboriosos Albertum Busek 1666 KGW177 347; Laboriosos ... Alexandrum Chodak... 1671 KGW177 782; Zagrodnicy ... Jędrzey Fortak 1703 KGR103 1205; Laborioso Jasko Duda 1705 KGR104 706; Laboriosus Hawrÿło Gaÿda 1724 KGR114 389; Laboriosi Jendruch Gieleta 1734 KGR117 741; Zagrodnicy ... Tywon Jchniatiuk 1736 KGR118 376; Chłop Michał Jarmolczuk 1740 KGR120 239; Pracowici ... Petro Gorliczenko ... 1760 KGR123 1425; Laboriosum Antonium Jastrzębski 1764 KGR125 1420; Pracowitego Andrzeya Wasylczuka 1770 KGR158 525. Такі змінні ідентифікатори особи іноді набували усіченого вигляду. Ймовірно, це залежало від стилю писаря, наприклад: Cmet. Albertus Kara3 1592 KZG3 911; Cmet. Stanislaus Maзur 1592 KZG3 911; Cmet. Stephan Toloczko 1592 KZG3 911; Labos. Mathias Orlik et Michael de villa Krzywe Subditi Gnosi Ludovici Budzinski 1655 KGW175 1544; Labsis Stanislao Tywon 1704 KGR104 386; Labsi ... Jwan Szlad ... 1713 KGR107 899; Labsus Marcin Tatusiak 1714 KGR108 15; Labsus Jaremko Tkaczÿk 1717 KGR109 297; Labsum Walko Pastuch 1768 KGR158 389.

Хоча прізвища у досліджуваний період не мали юридичного статусу, антропоніми, якими ідентифікували селян, демонструють певні ознаки стабільності. Це виявляється зокрема в тому, що спільне прізвище носили цілі генерації, наприклад: Laboriosi Joannes S3onka frater germanus olim Laboriosi Andruszko S3onka 1611 KZG26 506; Labsos Paulum Sołoducha Andream Sołoducha Fratres 1699 KGR102 498; Laboriosi Jędruch et Jasko Jasczaki fratres 1703 KGR103 987; Labsos Jarko Kloc et Tymko Kloc Fratres 1714 KGR108 133; Labsos ... Michaelem et Dacko Waszczukowie Fratres 1714 KGR108 133. Зафіксовано також одиничні приклади успадкування прізвищ дітьми, наприклад: Laboriosus Jaçko Pienka filius Laboriosi Jwan Pienka 1611 KZG26 541; Laboriosos Andruszko Onusczÿk chwetko onusczÿk filium ... 1671 KGW177 780.

В аналізованому матеріалі зібраних антропонімів фіксуємо також записи додаткових форм, які вказують, що друге після імені визначення не було стабільним, а процес творення прізвищ надалі тривав. Такого типу підтвердження стосуються всього досліджуваного періоду, наприклад: Laboriosi Alberti Bartoszczuk 1721 KGR112 200 // Poddani ...Woyciech Bartoszuk 1719 KGR110 961; Laboriosos ...Tÿmosz Czÿsz ... 1626 KZG29 492 // Laboriosus Thymosз Cзӥзyk de villa Woÿslawicze 1619 KZG27 1169; Laboriosum Steczko Demczak de Villa Koniuchy 1620 KZG15 156 // Laboriosis Steczko et Hrÿcзko Demcзukowic3 1621 KZG15 695; Labsum Nicolaum Wołczak 1686 KGW179 592 // Laboriosos ...Nicolaum Wołczko de villa Komorow 1669 KGW177 683; Chryc Homa 1765 ASK119 395 // Laboriosus Hryć Homiak 1747 KGR121 668; Jędruszek Hawryło 1747 KGR121 495 // Hawryło Jędruszuk 1730 KGR116 859; Laboriosos Wasko Kieca 1729 KGR116368 // Pracowitego Wasyla Kiecenka 1760 KGR123 1425; Labsum Hryc Kochanik 1702 KGR103 196 // Laboriosus Hryc Kochaniuk 1701 KZ65 387; Laboriosus Mathias Magiera 1730 KGR116 1037 // Laboriosos Mathiam Magierka 1730 KGR116 1037; Laboriosus Iwan Samuyło 1723 KP193 171 // Jwan Samuiluk 1765 ASK119 395. 
Результати й перспективи досліджень. До середини XVI століття у Грабовецькому старостаті серед селян переважала одночленна система онімної ідентифікації. Згодом, разом із потребою розширеної ідентифікації, доповнювалися патронімійні прізвища, які дорівнювали апелятивам, що частково називали географію походження людини, а також вказували на соціальний стан і походження особи. Додаткові елементи, присутні в досліджуваному матеріалі, вказують, що друге після імені визначення ще не було стабільним. Однак із часом цілі генерації мали спільні прізвища, що було ознакою стабілізації прізвищ серед селян. Результати дослідження історичної антропонімії Грабовецького старостату формують насамперед уявлення про способи ідентифікації мешканців цього регіону на межі України та Польщі, про міграційні та асимілятивні процеси. $\mathrm{y}$ перспективі це дозволить визначити інтенсивність контактів між сусідніми етносами на досліджуваній території.

\section{Список використаних джерел}

\section{Sources}

KZ1 - Księgi grodzkie grabowieckie, Księga zapisów (1502-1538), syg. 35/10/0/1/1

KZ51 - Księgi grodzkie grabowieckie, Księga zapisów (1600-1606), syg. 35/10/0/1/51

KZ52 - Księgi grodzkie grabowieckie, Księga zapisów (1607-1610), syg. 35/10/0/1/52

KZ53 - Księgi grodzkie grabowieckie, Księga zapisów (1615-1616), syg. 35/10/0/1/53

KZ54 - Księgi grodzkie grabowieckie, Księga zapisów (1617-1623), syg. 35/10/0/1/54

KZ55 - Księgi grodzkie grabowieckie, Księga zapisów (1623-1630), syg. 35/10/0/1/55

KZ56 - Księgi grodzkie grabowieckie, Księga zapisów (1631-1639), syg. 35/10/0/1/56

KZ57 - Księgi grodzkie grabowieckie, Księga zapisów (1640-1646), syg. 35/10/0/1/57

KZ58 - Księgi grodzkie grabowieckie, Księga zapisów (1647-1650), syg. 35/10/0/1/58

KZ59 - Księgi grodzkie grabowieckie, Księga zapisów (1650-1655), syg. 35/10/0/1/59

KZ60 - Księgi grodzkie grabowieckie, Księga zapisów (1655-1662), syg. 35/10/0/1/60

KZ61 - Księgi grodzkie grabowieckie, Księga zapisów (1665-1675), syg. 35/10/0/1/61

KZ62 - Księgi grodzkie grabowieckie, Księga zapisów (1675-1681), syg. 35/10/0/1/62

KZ63 - Księgi grodzkie grabowieckie, Księga zapisów (1680-1690), syg. 35/10/0/1/63

KZ64 - Księgi grodzkie grabowieckie, Księga zapisów (1691-1698), syg. 35/10/0/1/64

KZ65 - Księgi grodzkie grabowieckie, Księga zapisów (1699-1708), syg. 35/10/0/1/65

KP193 - Księgi grodzkie grabowieckie, Księga plenipotencji (1681-1732), syg. $35 / 10 / 0 / 4 / 193$

KP194 - Księgi grodzkie grabowieckie, Księga plenipotencji (1735-1753), syg. $35 / 10 / 0 / 4 / 194$

KP195 - Księgi grodzkie grabowieckie, Księga plenipotencji, (1754-1773), syg. 35/10/0/4/195

KP196 - Księgi grodzkie grabowieckie, Księga plenipotencji (1773-1783), syg. $35 / 10 / 0 / 4 / 196$

KGL278 - Księgi grodzkie grabowieckie [Listy do Jakuba Robakiewicza susceptanta grodzkiego grabowieckiego 1725, XVIII w.], syg. 35/10/0/8/278

KGL279 - Księgi grodzkie grabowieckie [Listy Ludwika Wilgi starosty grabowieckiego do Pawła Wydżgi wicesgerensa grodzkiego grabowieckiego, 1762-1765, 1769], syg. $35 / 10 / 0 / 8 / 279$

KGW161 - Księgi grodzkie grabowieckie, Księga wyroków (1581-1586), syg. 35/10/0/2/161 
KGW162 - Księgi grodzkie grabowieckie, Księga wyroków (1586-1593), syg. 35/10/0/2/162 KZG1 - Księgi ziemskie grabowieckie, Księga zapisów, relacji (1541-1590), syg. 35/3/0/-/1 KZG2 - Księgi ziemskie grabowieckie, Księga zapisów, relacji (1534-1559), syg. 35/3/0/-/2 KZG3 - Księgi ziemskie grabowieckie, Księga zapisów, relacji (1561-1597), syg. 35/3/0/-/3 KZG4 - Księgi ziemskie grabowieckie, Księga wyroków, relacji (1565-1570), syg. 35/3/0/-/4 KZG9 - Księgi ziemskie grabowieckie, Księga zapisów, relacji, wyroków (1590-1599), syg. 35/3/0/-/9

KZG15 - Księgi ziemskie grabowieckie, Księga zapisów, relacji, wyroków (1620-1625), syg. $35 / 3 / 0 /-/ 15$

KZG21 - Księgi ziemskie grabowieckie, Księga wyroków (1575-1579), syg. 35/3/0/-/21 KZG22 - Księgi ziemskie grabowieckie, Księga wyroków (1581-1586), syg. 35/3/0/-/22 KZG23 - Księgi ziemskie grabowieckie, Księga wyroków (1589-1594), syg. 35/3/0/-/23 KZG24 - Księgi ziemskie grabowieckie, Księga wyroków (1595-1600), syg. 35/3/0/-/24 KZG25 - Księgi ziemskie grabowieckie, Księga wyroków (1601-1608), syg. 35/3/0/-/25 KZG26 - Księgi ziemskie grabowieckie, Księga wyroków (1609-1617), syg. 35/3/0/-/26 KZG27 - Księgi ziemskie grabowieckie, Księga wyroków (1617-1619), syg. 35/3/0/-/27 KZG28 - Księgi ziemskie grabowieckie, Księga wyroków (1619-1636), syg. 35/3/0/-/28 KZG29 - Księgi ziemskie grabowieckie, Księga wyroków (1624-1629), syg. 35/3/0/-/29 KZG30 - Księgi ziemskie grabowieckie, Księga wyroków (1636-1644), syg. 35/3/0/-/30 KZG31 - Księgi ziemskie grabowieckie, Księga wyroków (1644-1658), syg. 35/3/0/-/31 KZG32 - Księgi ziemskie grabowieckie, Księga wyroków (1762-1777), syg. 35/3/0/-/32 KZG33 - Księgi ziemskie grabowieckie, Księga wpisów spraw (1762-1777), syg. 35/3/0/-/33 KZG34 - Księgi ziemskie grabowieckie, Księga pozwów (1773-1775), syg. 35/3/0/-/34 KGW175 - Księgi grodzkie grabowieckie, Księga wyroków (1651-1661), syg. 35/10/0/2/175 KGW176 - Księgi grodzkie grabowieckie, Księga wyroków (1658-1748), syg. 35/10/0/2/176 KGW177 - Księgi grodzkie grabowieckie, Księga wyroków (1660-1771), syg. 35/10/0/2/177 KGW178 - Księgi grodzkie grabowieckie, Księga wyroków (1676-1681), syg. 35/10/0/2/178 KGW179 - Księgi grodzkie grabowieckie, Księga wyroków (1682-1690), syg. 35/10/0/2/179 KGW180 - Księgi grodzkie grabowieckie, Księga wyroków (1691-1699), syg. 35/10/0/2/180 KGW181 - Księgi grodzkie grabowieckie, Księga wyroków (1700-1704), syg. 35/10/0/2/181 KGW182 - Księgi grodzkie grabowieckie, Księga wyroków (1711-1722), syg. 35/10/0/2/182 KGW183 - Księgi grodzkie grabowieckie, Księga wyroków (1723-1733), syg. 35/10/0/2/183 KGW185 - Księgi grodzkie grabowieckie, Księga wyroków (1673-1700), syg. 35/10/0/2/184 KGR73 - Księgi grodzkie grabowieckie, Księga relacji (1559-1623), syg. 35/10/0/3.1/73 KGR102 - Księgi grodzkie grabowieckie, Księga relacji (1699-1701), syg. 35/10/0/3.1/102 KGR103 - Księgi grodzkie grabowieckie, Księga relacji (1702-1703), syg. 35/10/0/3.1/103 KGR104 - Księgi grodzkie grabowieckie, Księga relacji (1704-1705), syg. 35/10/0/3.1/104 KGR105 - Księgi grodzkie grabowieckie, Księga relacji (1710-1711), syg. 35/10/0/3.1/105 KGR106 - Księgi grodzkie grabowieckie, Księga relacji (1712), syg. 35/10/0/3.1/106 KGR107 - Księgi grodzkie grabowieckie, Księga relacji (1713-1714), syg. 35/10/0/3.1/107 KGR108 - Księgi grodzkie grabowieckie, Księga relacji (1714-1715), syg. 35/10/0/3.1/108 KGR109 - Księgi grodzkie grabowieckie, Księga relacji (1717), syg. 35/10/0/3.1/109 KGR110 - Księgi grodzkie grabowieckie, Księga relacji (1718-1719), syg. 35/10/0/3.1/110 KGR111 - Księgi grodzkie grabowieckie, Księga relacji (1720), syg. 35/10/0/3.1/111 KGR112 - Księgi grodzkie grabowieckie, Księga relacji (1721), syg. 35/10/0/3.1/112 KGR113 - Księgi grodzkie grabowieckie, Księga relacji (1722-1723), syg. 35/10/0/3.1/113 KGR114 - Księgi grodzkie grabowieckie, Księga relacji (1724-1725), syg. 35/10/0/3.1/114 KGR115 - Księgi grodzkie grabowieckie, Księga relacji (1726-1728), syg. 35/10/0/3.1/115 KGR116 - Księgi grodzkie grabowieckie, Księga relacji (1729-1730), syg. 35/10/0/3.1/116 KGR117 - Księgi grodzkie grabowieckie, Księga relacji (1731-1735), syg. 35/10/0/3.1/117 KGR118 - Księgi grodzkie grabowieckie, Księga relacji (1735-1737), syg. 35/10/0/3.1/118 
KGR119 - Księgi grodzkie grabowieckie, Księga relacji (1738-1739), syg. 35/10/0/3.1/119 KGR120 - Księgi grodzkie grabowieckie, Księga relacji (1740-1742), syg. 35/10/0/3.1/120 KGR121 - Księgi grodzkie grabowieckie, Księga relacji (1743-1749), syg. 35/10/0/3.1/121 KGR122 - Księgi grodzkie grabowieckie, Księga relacji (1757-1759), syg. 35/10/0/3.1/122 KGR123 - Księgi grodzkie grabowieckie, Księga relacji (1759-1760), syg. 35/10/0/3.1/123 KGR124 - Księgi grodzkie grabowieckie, Księga relacji (1760-1761), syg. 35/10/0/3.1/124 KGR125 - Księgi grodzkie grabowieckie, Księga relacji (1762-1764), syg. 35/10/0/3.1/125 KGR126 - Księgi grodzkie grabowieckie, Księga relacji (1765-1767), syg. 35/10/0/3.1/126 KGR158 - Księgi grodzkie grabowieckie, Księga relacji (1765-1771), syg. 35/10/0/3.1/158 KM1 - Księgi miasta Grabowca, Księga radziecko-ławnicza (1643-1646), syg. 35/32/0/-/1 KM2 - Księgi miasta Grabowca, Księga radziecko-ławnicza (1643-1654), syg. 35/32/0/-/2 KM3 - Księgi miasta Grabowca, Księga radziecko-ławnicza (1643-1660), syg. 35/32/0/-/3 KM4 - Księgi miasta Grabowca, Księga radziecko-ławnicza (1647-1648), syg. 35/32/0/-/4 KM5 - Księgi miasta Grabowca, Księga radziecko-ławnicza (1708-1741), syg. 35/32/0/-/5 KM6 - Księgi miasta Grabowca, Księga radziecko-ławnicza (1740-1754), syg. 35/32/0/-/6 KM7 - Księgi miasta Grabowca, Księga radziecko-ławnicza (1754-1764), syg. 35/32/0/-/7 KM8 - Księgi miasta Grabowca, Księga radziecko-ławnicza (1764-1767), syg. 35/32/0/-/8 KM9 - Księgi miasta Grabowca, Księga radziecko-ławnicza (1764-1774), syg. 35/32/0/-/9 KM10 - Księgi miasta Grabowca, Księga radziecko-ławnicza (1768-1771), syg. 35/32/0/-/10 ASK119 - Archiwum Skarbu Koronnego, Lustracja starostw i królewszczyzn w powiecie grabowieckim (1765 r.), syg. LVI syg. 76

ASK125 - Archiwum Skarbu Koronnego, Lustracja starostwa grabowieckiego z 1662 roku, Dział XLVI syg. 125

KGS197 - Księgi grodzkie grabowieckie, Rejestry spraw (1595-1630), syg. 35/10/0/5/197.

\section{Список використаної літератури References}

Arkuszyn, Hryhorii. „Imiona mieszkańców gminy Wola Uhruska”. Gmina Wola Uhruska na tle Euroregionu Bug. Język i kultura, pod red. F. Czyżewskiego. Wola Uhruska, 2003, s. 181-205.

Arkuszyn, Hryhorii. „Motywacja przezwisk mieszkańców gminy Wola Uhruska”. Gmina Wola Uhruska na tle Euroregionu Bug. Język i kultura, pod red. F. Czyżewskiego. Wola Uhruska, 2003, s. 205-11.

Czopek, Barbara. Nazwy miejscowe dawnej ziemi chełmskiej i bełskiej (w granicach dzisiejszego państwa polskiego). Wrocław, 1988.

Czyżewski, Feliks, Warchoł, Stefan. Polskie i ukraińskie teksty gwarowe ze wschodniej Lubelszczyzny. Lublin, 1998.

Dacewicz, Leonarda. Nazewnictwo kobiet $w$ dawnym powiecie mielnickim (XVI-XVII). Białystok, 1994.

Horn, Maurycy. „Zaludnienie województwa bełskiego w 1630 r.” Roczniki Dziejów Społecznych i Gospodarczych, t. 21, 1959, s. 67-291.

Jabłonkowski, Aleksander. Polska XVI wieku pod względem geograficzno-statystycznym. Źródła dziejowe, T. XVIII, cz. 2, Ruś Czerwona. Warszawa, 1903, s. 178-93.

Jaroszyński, Wacław. Siedem wieków Grabowca. Lublin, 1991.

Kojder, Marcin. Antroponimia historyczna starostwa hrubieszowskiego w XVII-XVIII wieku. Lublin, 2014.

Kojder, Marcin. Antroponimia historyczna wiernych chełmskiej diecezji grecko-unickiej (16621810). Lublin, 2019.

Kość, Józef. „Z historii polsko-ukraińskich związków językowych we wschodniej Lubelszczyźnie”. Między Wschodem a Zachodem. Cz. 4. Zjawiska językowe na pograniczu polsko-ruskim, pod red. J. Bartmińskiego i M. Łesiowa. Lublin, 1992, s. 101-10. 
Kość, Józef. „Polszczyzna grekokatolików chełmskich w XVII wieku”. Prace Językoznawcze, nr. 24, 1996, s. 39-48.

Kuraszkiewicz, Władysław. „Z przeszłości narzecza zamojskiego”. Pamiętnik Lubelski, t. 3, 1938, s. 201-46.

Mytnik, Irena. Antroponimia Wołynia w XVI - XVIII wieku. Warszawa, 2010.

Mytnik, Irena. Imiennictwo ziemi chełmskiej w XVI-XVII wieku. Warszawa, 2017.

Olejnik, Marek. Antroponimia starostwa grabowieckiego (XVI-XVIII w.). Lublin, 2019.

Rieger, Janusz. Imiennictwo ludności wiejskiej w ziemi sanockiej i przemyskiej $w X V$ w. Wrocław, 1977.

Szulowska, Wanda. Imiennictwo dawnej ziemi halickiej i lwowskiej. Warszawa, 1992.

Wolnicz-Pawłowska, Ewa. Antroponimia łemkowska na tle polskim i słowackim XVI-XIX wieku. Warszawa, 1993.

Стаття надійшла до редколегії 11.09.2020 